\title{
Influence of GABA on neurons of the gustatory zone of the rat nucleus of the solitary tract
}

\author{
Limei Wang ${ }^{a}$ and Robert M. Bradley ${ }^{a, b}$ \\ "Department of Biologic and Materials Sciences, School of Dentistry, University of Michigan, MI 48109-1078 (USA) and \\ ${ }^{b}$ Department of Physiology, Medical School, University of Michigan, MI 48109-0622 (USA)
}

(Accepted 15 February 1993)

Key words: $\gamma$-Aminobutyric acid; Taste; Inhibition; Synaptic transmission; Brain slice

\begin{abstract}
The role of $\gamma$-aminobutyric acid (GABA) as an inhibitory neurotransmitter in the rostral, gustatory zone of the nucleus of the solitary tract (rNST) was examined using whole cell recordings in brain slices of the adult rat medulla. Superfusion of GABA resulted in a concentration-dependent reduction in input resistance in $68 \%$ of the neurons in rNST. The change in input resistance was often accompanied by membrane hyperpolarization. The effect of GABA was a direct action on the postsynaptic membrane since it could be elicited when synaptic transmission was blocked by tetrodotoxin or in a low $\mathrm{Ca}^{2+}$ and high $\mathrm{Mg}^{2+}$ perfusing solution. The mean reversal potential of the GABA effect was about $-60 \mathrm{mV}$, determined by applying GABA at different holding potentials, or from the intersection of current-voltage curves measured in control saline and saline containing GABA. When neurons were separated into groups based on intrinsic membrane properties, some neurons in each group responded to GABA. Superfusion of the slices with either the $\mathrm{GABA}_{\mathrm{A}}$ agonist, muscimol, or the GABA $\mathrm{B}_{\mathrm{B}}$ agonist, baclofen, caused a decrease in input resistance accompanied by membrane hyperpolarization. The $\mathrm{GABA}_{\mathrm{A}}$ antagonist bicuculline either totally or partially blocked the neuronal response to GABA and blocked the response to muscimol but did not antagonize responses to baclofen. Superfusion of the $\mathrm{GABA}_{\mathrm{B}}$ antagonist phaclofen depressed the membrane responses to GABA. The use of the GABA $\mathrm{A}_{\mathrm{A}}$ and GABA $\mathrm{B}$ agonists and antagonists demonstrates that some neurons in rNST have both $\mathrm{GABA}_{\mathrm{A}}$ and $\mathrm{GABA}_{\mathrm{B}}$ receptors. Since most rNST neurons studied respond to GABA, inhibition probably plays a major role in sensory processing by the rNST.
\end{abstract}

\section{INTRODUCTION}

The rostral extent of the nucleus of the solitary tract (rNST) is the site of termination of afferent gustatory fibers $^{4,22}$. Morphological analysis of Golgi stained material of the gustatory zone of the rat rNST shows that it contains at least three neuron types ${ }^{28,29}$. Fusiform neurons are characterized by an elongated soma and two large primary dendrites; multipolar neurons have a stellate-shaped soma and three to five primary dendrites; ovoid neurons have small soma diameters and two or three primary dendrites. The small ovoid neurons connect locally in the medulla whereas the multipolar and fusiform neurons project rostrally to the parabrachial nucleus ${ }^{28,55}$. Multipolar neurons are reportedly the predominant rostral projection neuron in the rat $^{27}$.

Using whole cell recordings in slice preparations of the rat gustatory NST we have shown that neurons can also be separated into groups based on their neurophysiological discharge pattern ${ }^{5}$. Using a hyperpolarization-depolarization pulse paradigm to distinguish cell types, we characterized four neural groups. Hyperpolarization of Group I neurons altered the repetitive discharge pattern initiated by membrane depolarization to an irregular pattern. Hyperpolarization of Group II neurons either delayed the occurrence of the first action potential, or increased the length of the first interspike interval in the action potential train produced by membrane depolarization. Hyperpolarization least affected the discharge pattern of Group III neurons. Hyperpolarization of Group IV neurons shortened the length of the action potential burst produced by membrane depolarization. The neurons in these four groups also differed in other passive membrane properties 5 . 
It is apparent, therefore, that membrane hyperpolarization of rNST neurons has a marked influence on the pattern of action potentials initiated by depolarization. In vivo membrane hyperpolarization is presumably the result of inhibitory synaptic activity. Because the inhibitory neurotransmitter $\gamma$-aminobutyric acid (GABA) has been shown to play a major role in the control of cardiovascular, respiratory and swallowing activity in the caudal NST ${ }^{10,26,31,44,53}$ and because neurons in the rNST of rat have been shown to be GABAergic using immunocytochemical techniques ${ }^{28}$, we examined the influence of GABA on neurons of the gustatory rNST using whole cell recording in a brain slice preparation of the rat medulla.

\section{MATERIALS AND METHODS}

\section{Tissue preparation}

Adult rat rNST slices were prepared and maintained as described elsewhere ${ }^{5}$. Briefly, rats weighing $120-250 \times g$ were anesthetized with sodium pentobarbital $(50 \mathrm{mg} / \mathrm{kg})$, and the brainstem removed. Four, coronal, $400 \mu \mathrm{m}$ slices containing the rostral $1.6 \mathrm{~mm}$ of the NST were cut on a Vibratome. After incubation in oxygenated, room temperature, physiological saline for at least one hour, a slice was transferred to a recording chamber with a wide-mouthed pipette. The slice was maintained at $32^{\circ} \mathrm{C}$ and superfused with physiological saline at a rate of $1.5-2.0 \mathrm{ml} / \mathrm{min}$. The physiological saline contained (in mM): $\mathrm{NaCl} 124, \mathrm{KCl} 5, \mathrm{CaCl}_{2} 2.5, \mathrm{MgSO}_{4} 1.3, \mathrm{NaHCO}_{3}$ $26, \mathrm{KH}_{2} \mathrm{PO}_{4} 1.25$, glucose 25 ; the solution was gassed with $95 \% \mathrm{O}_{2}$, $5 \% \mathrm{CO}_{2}$ to give a $\mathrm{pH}$ of 7.4 .

\section{Neurophysiology}

Whole cell recordings were made using the technique described by Blanton et al. ${ }^{2}$. Patch electrodes were pulled in two stages from $1.5 \mathrm{~mm}$, outside diameter, borosilicate filament glass (WPI, TW150F50F-4) on a Narishige PP83 electrode puller, and had a tip resistance of 5-8 $\mathrm{M} \Omega$ (bubble numbers of $5.8-6^{34}$ ). They were filled with a solution containing (in $\mathrm{mM}$ ) $\mathrm{K}$-gluconate 130, HEPES 10 , EGTA $10, \mathrm{CaCl}_{2} 1$, ATP 2, adjusted to a pH of 7.35 with $\mathrm{KOH}$. The electrodes were positioned over the rNST, which was easily identified through the dissecting microscope when transluminated from below. The indifferent electrode was a $\mathrm{Ag}-\mathrm{AgCl}$ wire connected to the extracellular solution via an agar bridge. After a successful recording, the position of the patch pipette was noted on a standard series of diagrams of the brain slices.

\section{Data analysis}

Once a gigaohm seal had been obtained and the patch ruptured, current was injected into the neurons using the bridge circuit of an Axoclamp 2A (Axon Instruments) in current clamp mode. This was balanced after breakthrough and was checked throughout the recording. Changes in neuronal input resistance were monitored by injecting negative constant current pulses $(100 \mathrm{~ms}, 0.1 \mathrm{nA})$ into the neurons at a frequency of $0.15 \mathrm{~Hz}$ and the resultant changes in membrane potential were recorded continuously on a pen recorder at slow speed (see for example Fig. 2A). This pulse length was sufficient to charge the membrane to a steady state level (see Fig. 5). In addition, current stimulation protocols were performed and voltage data acquired and analyzed under computer control using the pCLAMP program (Axon Instruments) throughout the experiments. To be considered a response to $10^{-3} \mathrm{M}$ GABA the input resistance of the neuron, measured at the point of maximum effect, had to decrease by at least $10 \%$ of control values and the membrane potential had to change by more than $1 \mathrm{mV}$. Data are presented as means \pm S.E. and statistical significance $(P<0.05)$ was assessed using paired $t$-tests unless otherwise indicated.

\section{Pharmacology}

With a system of valves, physiological saline containing either GABA $\left(10^{-4}-10^{-3} \mathrm{M}\right)$, muscimol $\left(10^{-3} \mathrm{M}\right)$, bicuculline $\left(10^{-4} \mathrm{M}\right)$, baclofen $\left(10^{-4} \mathrm{M}\right)$ or phaclofen $\left(10^{-3}-1.5 \times 10^{-3} \mathrm{M}\right)$ was superfused over the slices. Experimental saline containing the pharmacological agent was exchanged for the control saline for $\frac{1}{2} \mathrm{~min}$, and took $3 \mathrm{~min}$ to arrive at the slice chamber. Control saline was then superfused over the slice for at least $4 \mathrm{~min}$, before switching to another concentration of GABA or GABA receptor agonists and antagonists. All drugs were obtained from Sigma Chemical Co except phaclofen, which was supplied by Research Biochemicals Incorporated. Drug doses used were based on those found effective by other investigators ${ }^{17,25}$.

\section{Neuron classification}

As in previous studies ${ }^{5,13}$, neurons were separated into groups using a current injection paradigm in which the neurons were depolarized following membrane hyperpolarization of increasing durations.

\section{RESULTS}

Whole cell recordings were made from over 200 neurons in 124 rNST slices obtained from 85 rats. Of these neurons 131 were studied because they had a stable resting membrane potential, a spike overshoot of at least $10 \mathrm{mV}(26 \mathrm{mV}, \pm 0.9$, range $10-53)$, and an input resistance greater than $100 \mathrm{M} \Omega$. The mean depth

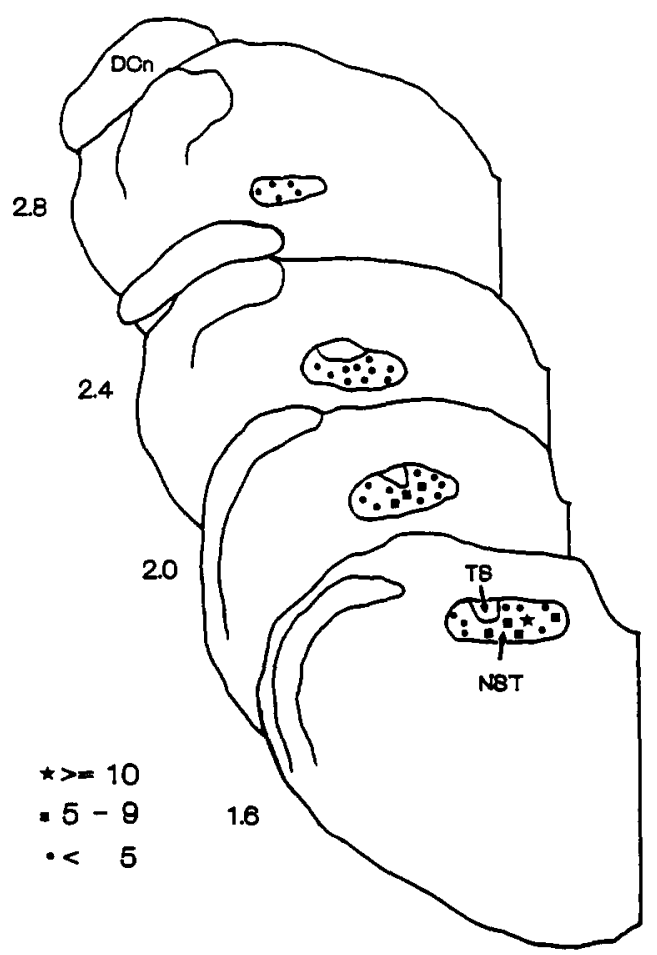

Fig. 1. Diagrams of 4 coronal slices of the brain stem containing the rostral pole of the NST. The recording site for all neurons is shown by different symbols representing the number of neurons recorded at each site. The numbers on the left indicate mm rostral to obex. DCn, dorsal cochlear nucleus; NST nucleus of the solitary tract; TS, tractus solitarius. 
of the neurons in the slice was $77 \mu \mathrm{M}( \pm 5.2$, range 0 to 280). Mean resting membrane potentials of these neurons were $-48 \mathrm{mV}( \pm-0.76$, range -31 to -86$)$. Action potential amplitude ranged from 43 to $107 \mathrm{mV}$ $(74 \pm 1.1)$, with a mean duration measured at half amplitude of $1.4 \mathrm{~ms}( \pm 0.03)$. Input resistance, determined from responses to a $100 \mathrm{~ms},-100 \mathrm{pA}$ hyperpolarizing current pulse, varied between 151 and 1577 $\mathrm{M} \Omega(517 \pm 24.6)$. These values are similar to those reported by us and other investigators using whole cell recordings in brain slices ${ }^{2,5,45,48}$.

\section{Membrane responses to $G A B A$}

Superfusion of GABA $\left(10^{-3} \mathrm{M}\right)$ resulted in a reduction in input resistance in 89 of 131 neurons (68\%), distributed throughout the rNST. The location of these neurons in coronal slices is identified in Fig. 1. Neurons that responded to GABA were situated at similar depths to neurons that did not respond to GABA

A
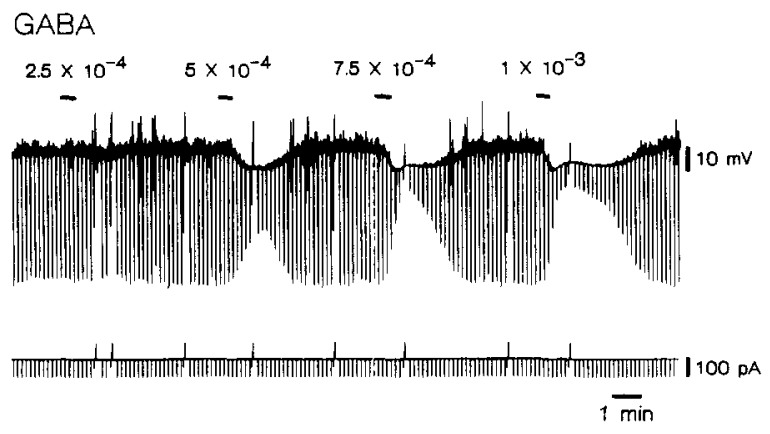

B

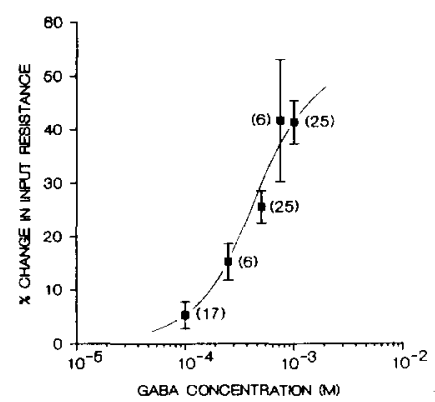

Fig. 2. A: membrane responses (upper trace) of a rostral NST neuron to constant current hyperpolarizing pulses (lower trace) applied through the patch electrode during superfusion of the slice with different concentrations of GABA (horizontal bars). Between applications the slice was superfused with control saline. This neuron responded with increasing levels of membrane hyperpolarizations and reduction in input resistance (indicated by reductions in the hyperpolarizing membrane response) to higher concentrations of GABA. During the experiment computer generated current injection protocols used for analyses of changes in membrane properties were applied and interrupt the regular hyperpolarizing current pulses seen in the current trace. Resting membrane potential $=-43 \mathrm{mV}$. B: concentration-response curves of $\%$ change in input resistance to increasing concentrations of GABA. Numbers of measurements at each concentration are shown in parentheses. The curve was fitted by eye. Bars $=$ S.E. of mean

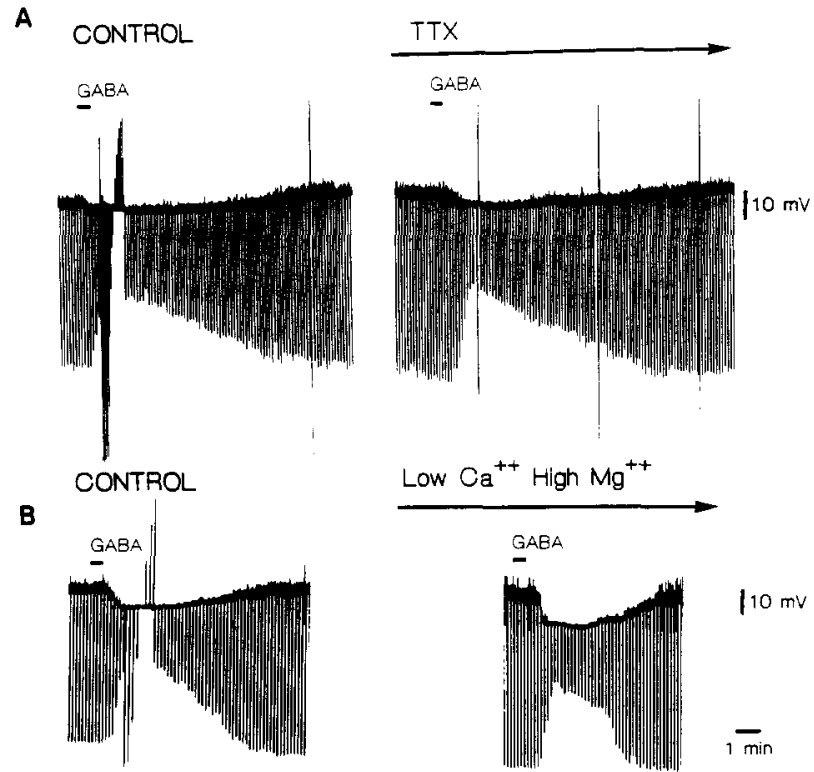

Fig. 3. A: membrane response of a rNST neuron to superfusion of $10^{-3} \mathrm{M}$ GABA control saline and in the presence of $0.5 \times 10^{-6} \mathrm{M}$ TTX. Resting membrane potential $=-52 \mathrm{mV}$. B: membrane response of a rNST neuron to superfusion of $10^{-3} \mathrm{M}$ GABA in control saline and in the presence of low $\mathrm{Ca}^{2+}$ and high $\mathrm{Mg}^{2+}(0.2 \mathrm{mM}$ $\mathrm{Ca}^{2+}, 11.4 \mathrm{mM} \mathrm{Mg}^{2+}$ ) perfusing solution. Computer generated hyperpolarizing and depolarizing current pulses used to measure membrane characteristics interrupt the hyperpolarizing membrane

responses in all traces. Resting membrane potential $=-52 \mathrm{mV}$.

(mean depth of responders $=76 \mu \mathrm{M} \pm 6.5$, range 0 280 ; mean depth of non-responders $=80 \mu \mathrm{M} \pm 8.7$, range 0-250).

Application of a concentration series of GABA $(1 \times$ $10^{-4}$ to $1 \times 10^{-3} \mathrm{M}$ ) revealed a dose-dependent reduction in input resistance (Fig. 2A). With $10^{-3} \mathrm{M}$ GABA the extent of the reduction averaged $34 \mathrm{M} \Omega( \pm 2$, range $13-86, n=82$ ). Membrane resistance returned to control levels within 3-5 min of termination of the GABA application. The change in membrane resistance was often accompanied by membrane hyperpolarization (mean hyperpolarization for $10^{-3} \mathrm{M} \mathrm{GABA}$ $=-3.5 \mathrm{mV} \pm-0.3$, range -13 to $-1.0, n=75$ ) (Fig. 2A).

A concentration-response curve of the reduction in input resistance produced by superfusion with GABA is shown in Fig. 2B. At least 3 GABA concentrations were used on each neuron, but not all concentrations were used on all neurons (number of observations shown in parentheses). For some neurons the lower concentrations did not affect membrane resistance but these have been included in the calculations of the mean value for each concentration.

The effect of GABA was a direct action on the postsynaptic membrane since it could be elicited when synaptic transmission was blocked by tetrodotoxin (TTX $\left.0.5 \times 10^{-6} \mathrm{M}, n=6\right)$ or in a low $\mathrm{Ca}^{2+}$ high $\mathrm{Mg}^{2+}(0.2$ 
$\left.\mathrm{mM} \mathrm{Ca}{ }^{2+}, 11.4 \mathrm{mM} \mathrm{Mg}^{2+}, n=11\right)$ perfusing solution (Fig. 3A and B.). Analysis of the effect of GABA application on input resistance and membrane potential before and in the presence of TTX and low $\mathrm{Ca}^{2+}$ high $\mathrm{Mg}^{2+}$ revealed no significant change $(P>0.15)$.

The GABA reversal potential was found by applying GABA at different holding potentials (Fig. 4A), as well as from the intersection of current-voltage curves (Fig. 4B) measured in control saline and saline containing $10^{-3} \mathrm{M}$ GABA. Using both these methods the mean reversal potential was $-60.4 \mathrm{mV} \pm 1.7$ (range -43 to $-96, n=41$ ). The distribution of the reversal potentials is shown in Fig. $4 \mathrm{C}$, together with their normal distribution showing that most of the neurons tested have reversal potentials around $-60 \mathrm{mV}$.

\section{Membrane responses of different groups of neurons to $G A B A$}

Neurons were separated into groups using a current injection protocol consisting of a $200 \mathrm{pA}$ hyperpolarizing pulse of different lengths (50-200 ms) immediately followed by a long (1200 ms, $100 \mathrm{pA})$ depolarizing pulse (Fig. 5A-D). This method has been used previously by our laboratory to characterize rNST neurons ${ }^{5}$. Of the total neurons, 10 were classified as Group I, 53 as Group II, 50 as Group III and 18 as Group IV.

A

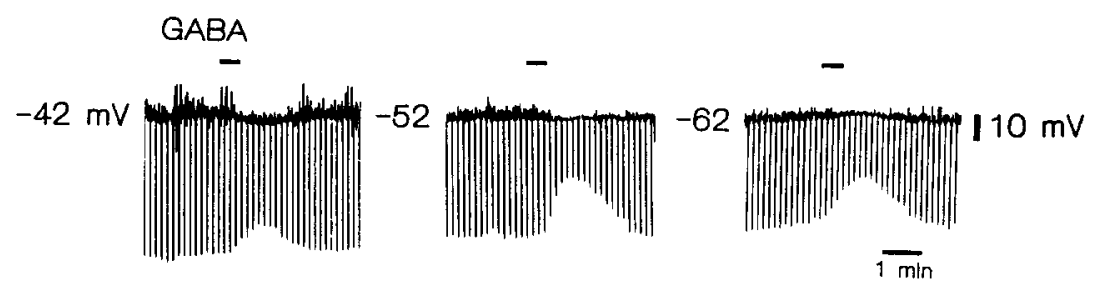

B

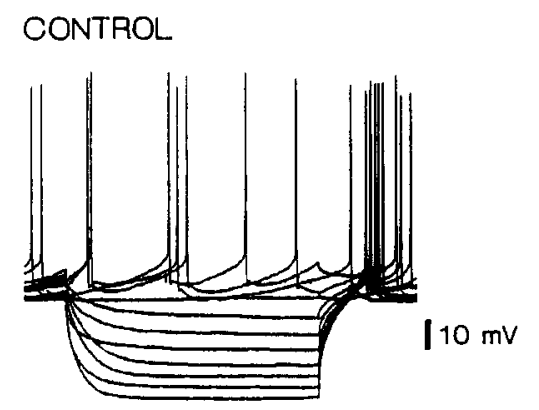

GABA
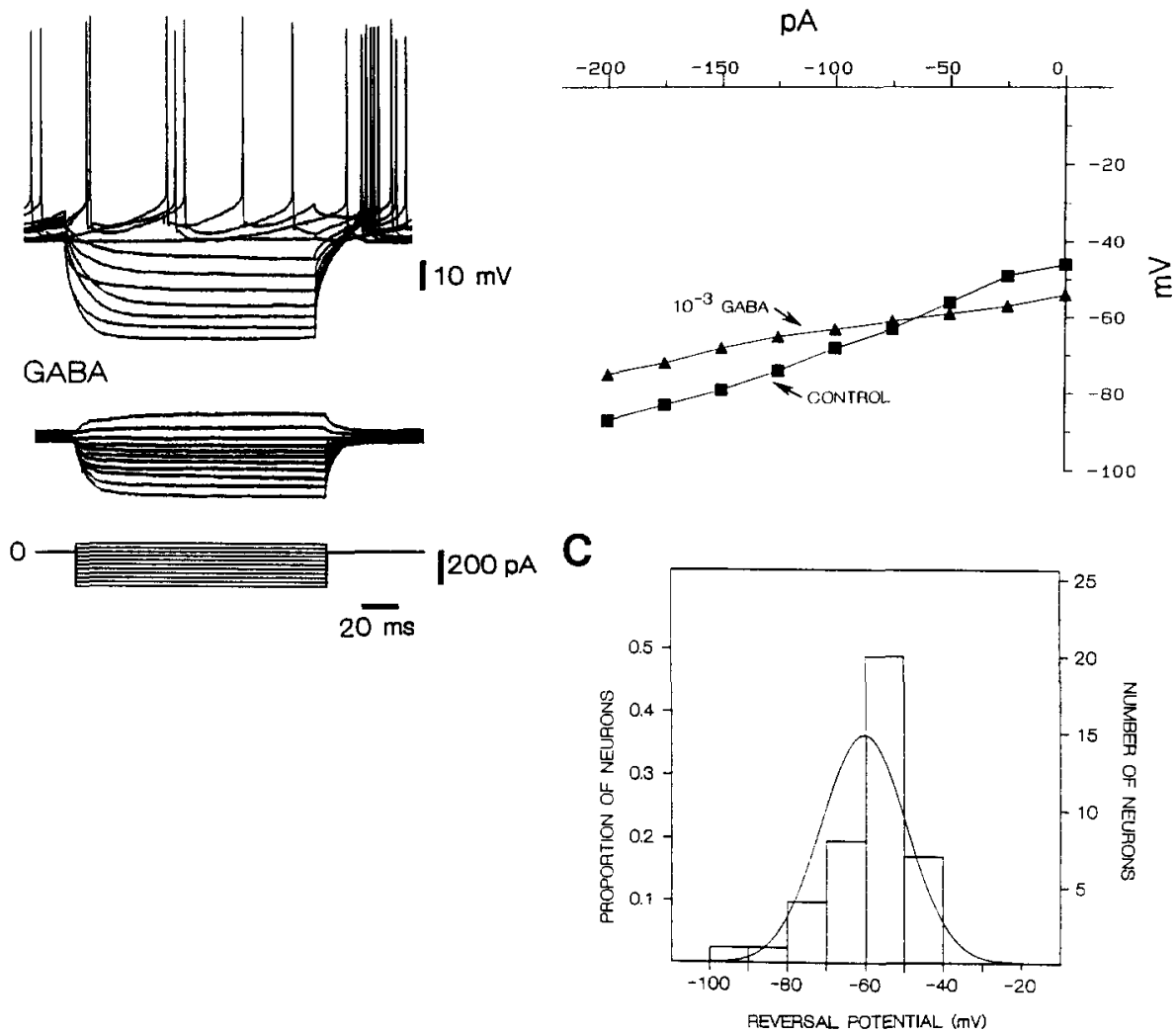

Fig. 4. A: membrane response of a rNST neuron to superfusion of $10^{-3} \mathrm{M}$ GABA in control saline at resting membrane potential levels and after the membrane potential had been hyperpolarized by current injection to a level of -52 and $-62 \mathrm{mV}$. The hyperpolarization produced by GABA reverses to become a depolarization at $-62 \mathrm{mV}$. B: current-voltage plot of a neuron in control saline and in saline containing $10^{-3} \mathrm{M}$ GABA. The membrane responses are shown on the left. Resting membrane potential $=-46 \mathrm{mV}$. C: distribution of the reversal potentials for 41 rNST neurons. A normal distribution has been fitted to these data and has a peak value close to $-60 \mathrm{mV}$. 
A
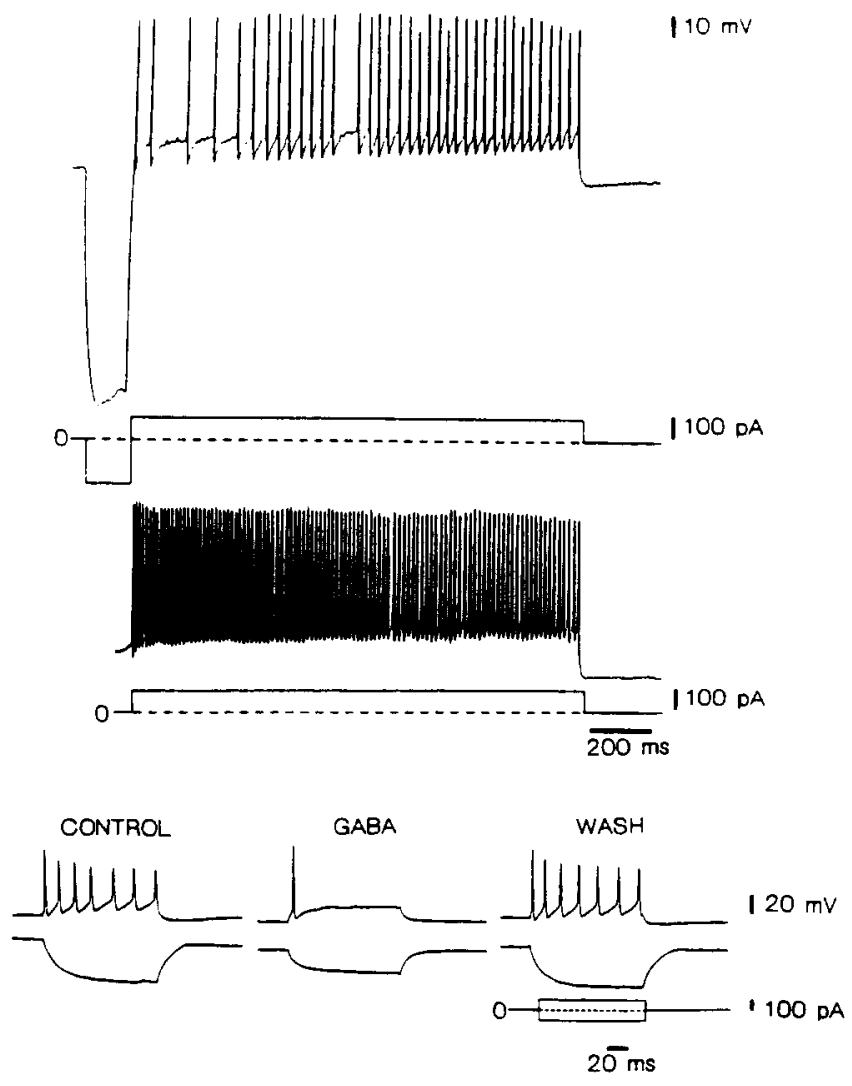

C
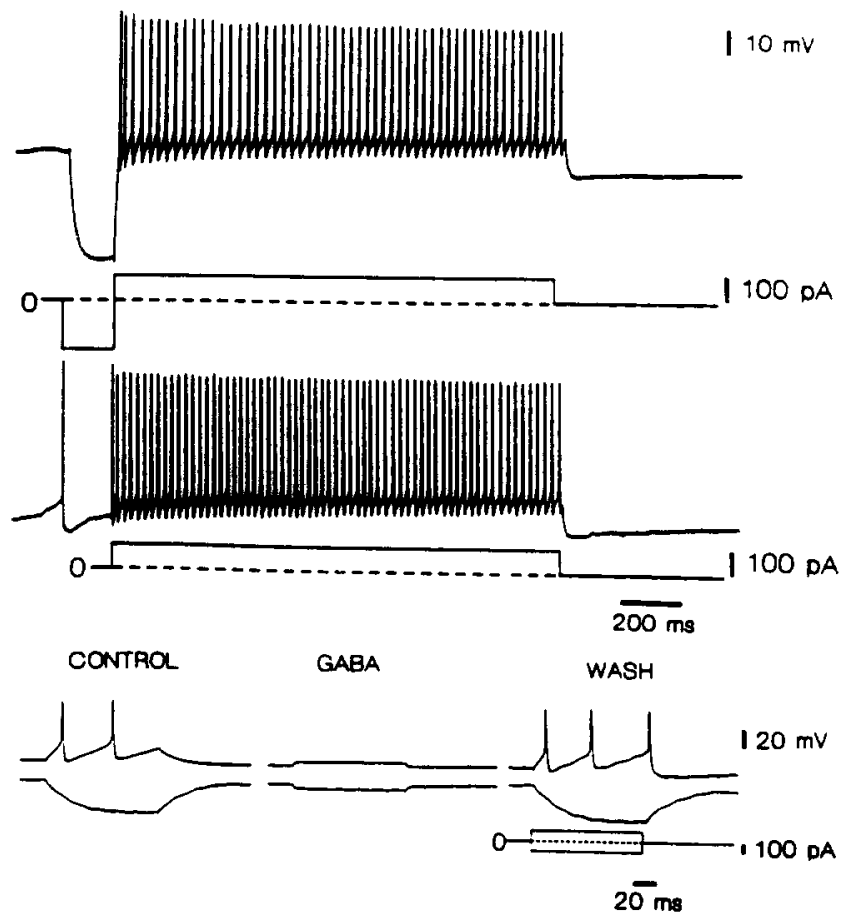

B
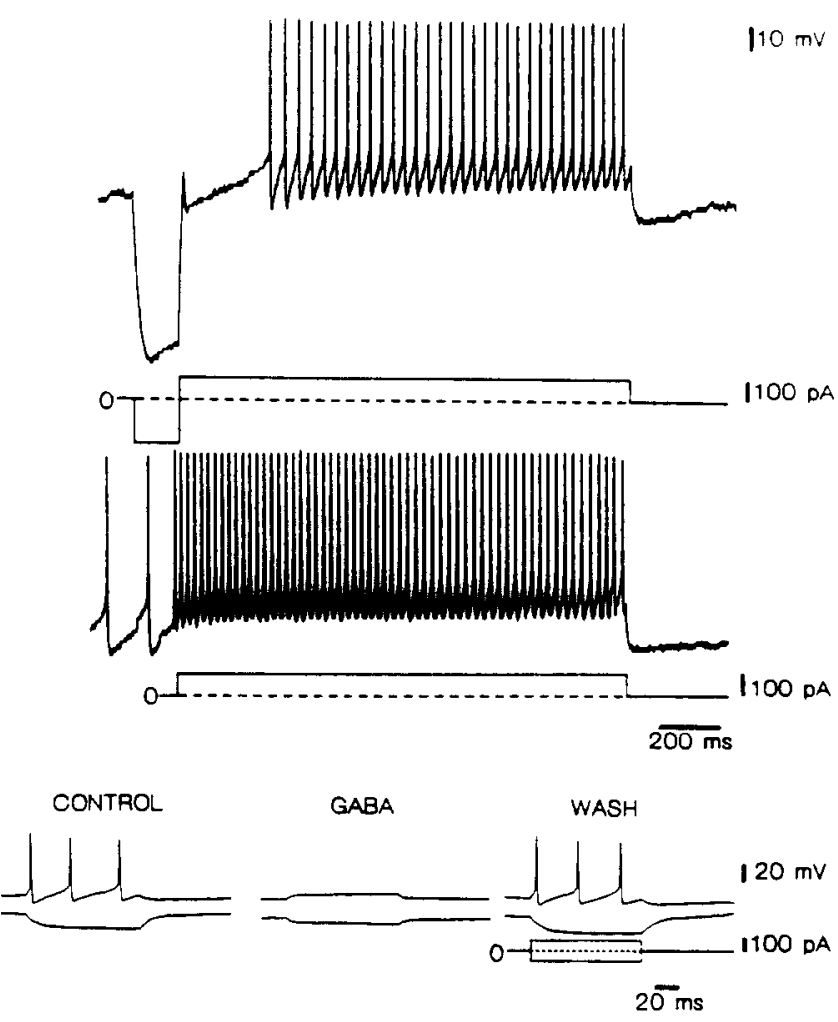

D
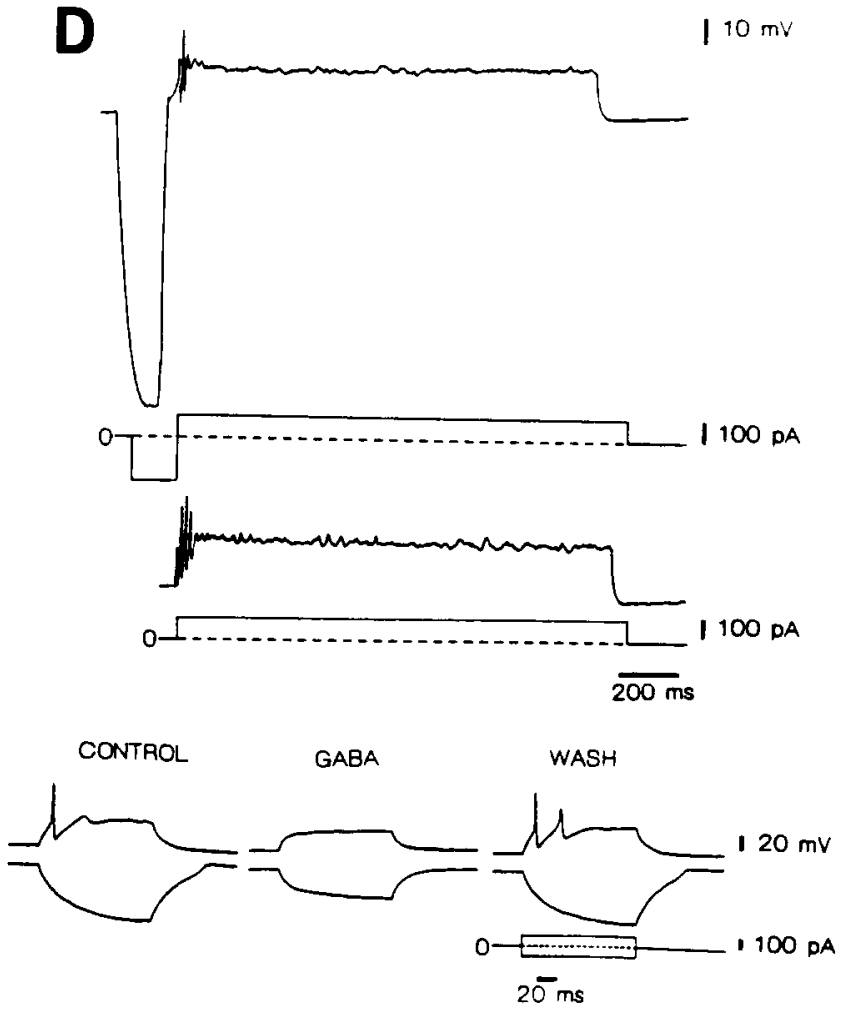
TABLE I

Effects of $10^{-3}$ GABA on neuron groups in the rostral NST

\begin{tabular}{lll}
\hline Group & $n$ & \% Neurons responding \\
\hline I & 10 & 50 \\
II & 53 & 76 \\
III & 50 & 62 \\
IV & 18 & 72 \\
\hline
\end{tabular}

Neurons in all groups were influenced by $10^{-3} \mathrm{M}$ GABA (Fig. 5A-D, lower panels), but not all the neurons in each group responded to GABA (Table I). There was no significant difference in the effect of GABA on the input resistance (analysis of variance, $\mathrm{F}_{1,3}=2.2, P=0.09$ ) or membrane potential (analysis of variance, $F_{1,3}=0.15, P=0.93$ ) across the four neuron groups.

Differentiation of GABA receptor types using agonists and antagonists

GABA is known to activate at least two distinct receptors: $\mathrm{GABA}_{\mathrm{A}}$ receptors coupled to $\mathrm{Cl}^{-}$channels and $\mathrm{GABA}_{\mathrm{B}}$ receptors coupled to a $\mathrm{K}^{+}$channel $^{3,17}$. To find out what types of GABA receptor exist on neurons of the rNST, we superfused the slices with either the $\mathrm{GABA}_{\mathrm{A}}$ agonist muscimol or the $\mathrm{GABA}_{\mathrm{B}}$ agonist baclofen. Both muscimol $\left(1 \times 10^{-3} \mathrm{M}\right)$ and baclofen $\left(1 \times 10^{-4} \mathrm{M}\right)$ caused a decrease in input resistance accompanied by membrane hyperpolarization (Fig. 6A). Seventeen neurons that responded to $10^{-3} \mathrm{M}$ GABA, were tested with muscimol and baclofen. All 17 responded to muscimol and 11 of these responded to baclofen as well. Thus, of the rNST neurons that respond to GABA, many respond to muscimol and baclofen (Fig. 6A) while others respond only to muscimol (Fig. 6B).

To further clarify the role of $\mathrm{GABA}_{\mathrm{A}}$ and $\mathrm{GABA}_{\mathrm{B}}$ receptors in synaptic processing in the rNST we used their respective antagonists. In 11 neurons that responded to $10^{-3} \mathrm{M}$ GABA, the $\mathrm{GABA}_{\mathrm{A}}$ antagonist bicuculline $\left(1 \times 10^{-4} \mathrm{M}\right)$ totally blocked the reduction in input resistance produced by GABA ( $n=11$, Fig. $7 b$ ). In other neurons responding to $10^{-3} \mathrm{M}$ GABA, bicuculline partially blocked the GABA induced reduction of input resistance (mean reduction compared with control value for $\mathrm{GABA}=42 \% \pm 11$, range $17-85$,
A
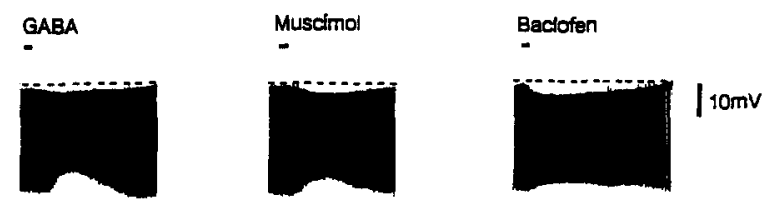

B
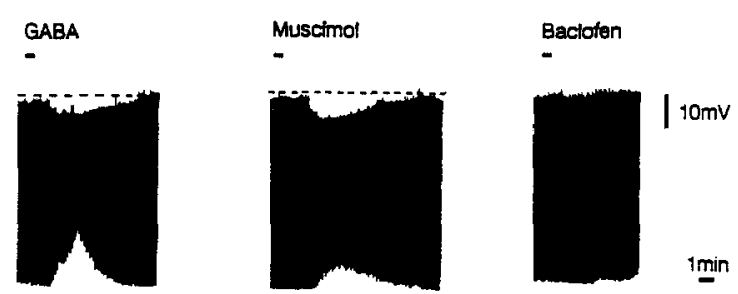

Fig. 6. A: recordings from a INST neuron that responded to superfusion of $10^{-3} \mathrm{M} \mathrm{GABA}, 10^{-5} \mathrm{M}$ muscimol, and $10^{-4} \mathrm{M}$ baclofen Resting membrane potential $=-48 \mathrm{mV}$. B: recordings from a rNST neuron that responded to superfusion of $10^{-3} \mathrm{M} \mathrm{GABA}, 10^{-5} \mathrm{M}$ muscimol, but did not respond to $10^{-4} \mathrm{M}$ baclofen. Resting membrane potential $=-52 \mathrm{mV}$.

$n=6)$ (Fig. 8b). Superfusion of the $\mathrm{GABA}_{\mathrm{B}}$ antagonist phaclofen $\left(10^{-3}\right.$ to $\left.1.5 \times 10^{-3} \mathrm{M}\right)$ depressed but did not block the membrane responses to GABA in 11 neurons tested (mean reduction compared with control value for $\mathrm{GABA}=42 \% \pm 5.2$, range $21-83 \%$ ) (Fig. $8 c$ ). The effect of bicuculline on membrane responses to muscimol and baclofen was tested in 4 neurons that responded to GABA. Bicuculline totally blocked the

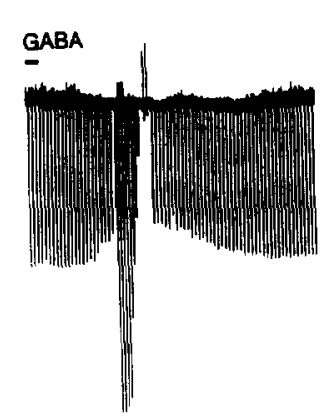

b

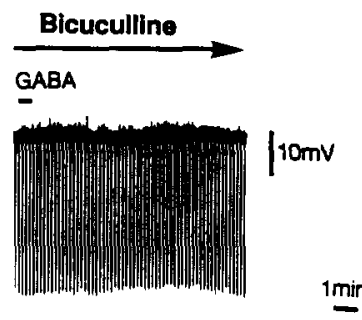

Fig. 7. Response of a rNST neuron to a application of $10^{-3} \mathrm{M}$ GABA (a) alone and in the presence of $10^{-4} \mathrm{M}$ bicuculline (b). Computer generated hyperpolarizing and depolarizing current pulses used to measure membrane characteristics interrupt the hyperpolarizing membrane responses in (a). Time of GABA application is indicated by the horizontal bar. Resting membrane potential = $-45 \mathrm{mV}$.

Fig. 5. A-D: responses of 4 different rNST neurons to a long $(1,200 \mathrm{~ms})$ depolarizing current pulse alone and preceded by a short hyperpolarizing current pulse. Using this current injection protocol neurons in the rNST can be separated into 4 groups. The hyperpolarizing pulse disrupts the regular discharge pattern in Group I neurons (A), causes a long delay in Group II neurons (B) and has the least effect on Group III neurons (C). Group IV neurons respond to depolarization with a short burst of action potentials (D). Below each panel is shown the response of each of these neurons to superfusion with $10^{-3} \mathrm{M}$ GABA. All of the neuron groups respond to GABA. Resting membrane potentials: $A=-41 \mathrm{mV}, B=-43 \mathrm{mV}, \mathrm{C}=-38 \mathrm{mV}, \mathrm{D}=-39 \mathrm{mV}$. 
a

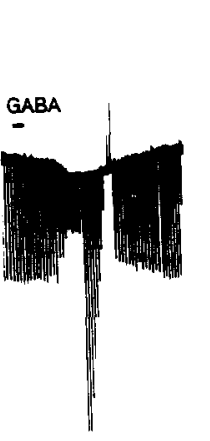

b
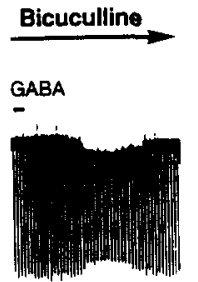

d

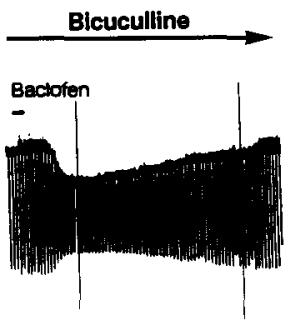

e

Bicuculline

Muscimo

$-$

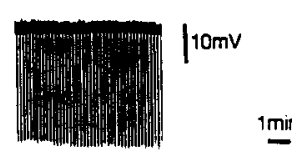

Fig. 8. Responses of a neuron to GABA receptor agonists and antagonists. This neuron responded to (a) $10^{-3} \mathrm{M}$ GABA. In the presence of $10^{-4} \mathrm{M}$ bicuculline the response to GABA was partially blocked (b), the response to muscimol was totally blocked (e) and the response to baclofen was unaffected (d). In the presence of $1.5 \times 10^{-3}$ $M$ phaclofen the response to GABA was depressed (c). Computer generated hyperpolarizing and depolarizing current pulses used to measure membrane characteristics interrupt the hyperpolarizing membrane responses in traces $8 \mathrm{a}, 8 \mathrm{~d}$. Resting membrane potential = $-47 \mathrm{mV}$.

neuronal response to muscimol (Fig. 8e) but did not antagonize responses to baclofen (Fig. 8d).

\section{DISCUSSION}

Like neurons in other parts of the central nervous system $^{3,43}$, the inhibitory neurotransmitter GABA hyperpolarizes and reduces the input resistance of neurons distributed throughout the gustatory zone of the rNST. The direct action of GABA is suggested by the persistence of its neuronal effects in the presence of TTX, or in a low $\mathrm{Ca}^{2+}$, high $\mathrm{Mg}^{2+}$ perfusing medium, procedures known to block synaptic transmission ${ }^{40,42}$.

There was a GABA effect in $68 \%$ of our neurons. Other investigators studying GABA rarely report neurons that do not respond to GABA. In fact it is often stated that all neurons tested respond to $\mathrm{GABA}^{8,37}$. Absence of a GABA response in some neurons could be due to failure of the drug to reach the neuron at sufficiently high concentrations to produce an effect. The concentrations over which GABA was effective in the present study are similar to those reported by others recording from neurons in brain slices ${ }^{7}$, but much higher than the concentrations found effective in isolated NST neurons ${ }^{35}$. These differences in effective-

ness of GABA may be due to penetration of GABA into the slice and GABA uptake by neurons and glia; therefore, the concentration at the recording site is much lower than the applied concentration ${ }^{41}$. However, since GABA responsive and non-responsive neurons were situated at similar depths in the slices, failure to respond to GABA could also be due to lack of GABA receptors.

When the $\mathrm{GABA}_{\mathrm{A}}$ agonist muscimol was superfused over the slices, all neurons tested showed a reduction in input resistance accompanied by membrane hyperpolarization, suggesting that these neurons have $\mathrm{GABA}_{\mathrm{A}}$ receptors. The effects of muscimol were antagonized by bicuculline. The use of the $\mathrm{GABA}_{\mathrm{B}}$ agonist baclofen and the $\mathrm{GABA}_{\mathrm{B}}$ antagonist phaclofen demonstrated that some neurons in the rostral NST have both $\mathrm{GABA}_{\mathrm{A}}$ and $\mathrm{GABA}_{\mathrm{B}}$ receptors. The fact that some neurons did not respond to baclofen might be due to washout of cell contents during whole cell recording, potentially leading to rapid rundown of the $G$ protein-coupled $\mathrm{GABA}_{\mathrm{B}}$ response.

That rNST neurons have both $\mathrm{GABA}_{\mathrm{A}}$ and $\mathrm{GABA}_{\mathrm{B}}$ receptors is supported by the reversal potential of the GABA effect. For most neurons the reversal potential was $-60 \mathrm{mV}$, a value similar to the GABA reversal potentials measured by other investigators suggesting the involvement of $\mathrm{Cl}^{-}$ions and $\mathrm{GABA}_{\mathrm{A}}$ receptors ${ }^{12,36,37,43}$. However, reversal potentials as low as $-96 \mathrm{mV}$ were measured for some neurons suggesting that other ions might be involved, possibly potassium ions associated with $\mathrm{GABA}_{\mathrm{B}}$ receptors.

Since most of the neurons responded to GABA, inhibition probably plays a major role in sensory processing by the rNST. Although investigators have reported that stimulation of the tongue with some taste stimuli occasionally causes inhibition of the ongoing spontaneous activity of second order neurons in the taste pathway, the predominant result of gustatory stimulation is excitation ${ }^{16,39,50}$. However, there is a growing body of evidence suggesting that inhibition may have a significant role in sensory processing in the rNST. Halpern and Nelson ${ }^{21}$ recorded from a region of the gustatory NST receiving input from both the chorda tympani and glossopharyngeal nerves innervating taste receptors on the anterior and posterior tongue, respectively. When the chorda tympani nerve input was eliminated by application of local anesthesia, the response to gustatory stimulation of the posterior tongue increased in magnitude and this was interpreted as removal of an inhibitory input. Extracellular recordings from single gustatory neurons receiving convergent input from anterior tongue and posterior oral cavity taste receptors revealed that when both areas are stimulated 
simultaneously, the response is not a simple summation of the neural responses to separate stimulation of anterior and posterior fields ${ }^{47}$. Rather, the response magnitude is between the response magnitudes evoked by stimulation of the individual fields. The weaker response seen to simultaneous stimulation of anterior or posterior receptive fields was hypothesized to be the result of inhibitory interaction.

Based on results of behavioral experiments in humans there is also evidence of inhibitory interactions between the glossopharyngeal and chorda tympani nerves at the level of the rNST. Damage or anesthesia of the chorda tympani nerve results in taste phantoms (aberrations of perceptual responses to taste stimuli) that disappear if the glossopharyngeal nerve receptive field is anesthetized ${ }^{33}$. Inhibitory interactions can also occur independently of convergent input derived from the chorda tympani and glossopharyngeal nerve. For example, the sodium channel blocker amiloride suppresses whole nerve and single fiber responses of the chorda tympani to $\mathrm{NaCl}^{6,14,19}$. When responses of the second order neurons in rNST were examined after application of amiloride to the tongue, the responses of the central neurons changed ${ }^{20}$. Many NST neurons increased their firing rate after the application of amiloride, which suggests that removal of the amiloride sensitive afferent input disinhibits these neurons ${ }^{38}$. There is also indication of a descending inhibitory influence on neurons in the rNST ${ }^{23}$.

Anatomical evidence also suggests that GABA has an important role in the gustatory zone of the NST. Using immunocytochemical techniques, GABA-containing neurons and puncta were found in the area of termination of the chorda tympani nerve in the NST ${ }^{28}$. The GABAergic neurons were small, with ovoid soma, resembling Golgi type II interneurons. In a recent study in which synaptic connections onto NST projection neurons were investigated in hamster, it was found that there was a high frequency of occurence of synapses onto projection neuron soma and proximal dendrites that are possibly of the inhibitory type ${ }^{54,56}$.

In a previous study we have shown that neurons of the rNST can be separated into 4 groups based on repetitive firing properties 5 . The neurons included in the current study were also separated into groups using similar techniques. Neurons in all groups were influenced by GABA, but not all the neurons in each group responded to GABA. Although we do not know the morphological characteristics of these neurons, we assume that our recordings probably originated from more than one morphological type. In fact, recent studies in our laboratory indicate that GABA influences projection neurons as well as local circuit neu- rons in the rNST in about equal proportions (King and Bradley, unpublished observations). In summary, anatomical studies, as well as electrophysiological and behavioral investigations suggest an important role for inhibition in the gustatory NST.

In the caudal NST inhibition has been shown to be important in a number of reflex functions. GABA has been localized in the caudal NST using immunocytochemical methods ${ }^{15,24,30,32}$. Iontophoresis ${ }^{1}$ and microinjections ${ }^{10,26,31}$ of GABA into the medial area of the caudal NST reduced activity in neurons receiving input from the carotid sinus and aortic nerves and caused an increase in blood pressure. Moreover, the inhibitory activity of GABA was antagonized by simultaneous injection of bicuculline ${ }^{31}$. Bicuculline applied alone resulted in an increase in the evoked activity of caudal NST neurons leading to the conclusion that a GABAergic inhibitory system, possibly modulated by afferent input, is functional in the caudal NST ${ }^{10,31}$.

The involvement of $\mathrm{GABA}_{\mathrm{A}}$ receptors in the inhibitory mechanisms of the caudal NST has been exam-

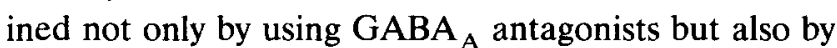
application of the $\mathrm{GABA}_{\mathrm{A}}$ agonist muscimol and nipecotic acid, a GABA uptake blocker ${ }^{10}$. Injection of baclofen, the $\mathrm{GABA}_{\mathrm{B}}$ agonist, was also effective in increasing blood pressure that was not blocked by $\mathrm{GABA}_{\mathrm{A}}$ antagonists. Thus, as we have observed in the rNST, both $\mathrm{GABA}_{A}$ and $\mathrm{GABA}_{\mathrm{B}}$ receptors are involved in the inhibitory mechanisms of the caudal NST $^{9,18,46}$

Other reflex mechanisms of the caudal NST involve inhibition. Investigations of the control of swallowing suggest that GABA neurons in the caudal NST exert a tonic inhibition of the medullary swallowing pattern generator ${ }^{53}$. Tonic GABAergic inhibition in the caudal NST has also been shown to be associated with the modulation of respiratory rhythm generation ${ }^{44}$. Iontophoresis of GABA and GABA $A$ agonists and antagonists onto respiratory neurons revealed that GABA release was probably responsible for the characteristic periodic inhibition exhibited by respiratory neurons ${ }^{11}$.

It is apparent, therefore, that GABA mediated inhibition is present throughout the rostro-caudal extent of the NST. In the caudal, visceral part of the NST, GABA is thought to tonically inhibit the nucleus. However, there is no direct evidence to indicate that the rNST is tonically inhibited.

Until recently the NST was thought to have a relatively straightforward influence on gustatory processing, primarily through excitatory synapses. When comparisons were made between the response characteristics of afferent taste fibers and second order neurons in the NST they were found to be similar ${ }^{51}$. There is 
evidence that convergence of afferent input occurs onto second order neurons ${ }^{47,52}$, but it is often assumed that the afferent information is passed on relatively unchanged. However, the results of the present study suggest that inhibition plays an important role in sensory processing by rNST neurons and that afferent input can potentially be altered or modulated by inhibitory action. Moreover, not all neurons in the rNST project to rostral brain areas. Others connect locally and are involved in the control of salivation and oromotor reflexes ${ }^{49}$. Inhibition may play an important role in these latter functions, where afferent inputs initiate motor patterns that require inhibition as an essential part of complex muscle coordination. During processing of gustatory information, inhibitory interactions might occur to enhance certain characteristics of the sensory stimulus. These anatomical and physiological studies suggest that the rNST is a complex sensory relay nucleus processing afferent gustatory and somatosensory information involving both excitatory and inhibitory interactions.

Acknowledgements. This work was supported by National Institutes of Health Grant DC00288 to R.M.B.

\section{REFERENCES}

1 Bennett, J.A., McWilliam, P.N. and Shepheard, S.L., A $y$ aminobutyric-acid-mediated inhibition of neurones in the nucleus tractus solitarius of the cat, $J$. Physiol., 392 (1987) 417-430.

2 Blanton, M.G., Lo Turco, J.J. and Kriegstein, A.R., Whole cell recording from neurons in slices of reptilian and mammalian cerebral cortex, J. Neurosci. Methods, 30 (1989) 203-210.

3 Bormann, J., Electrophysiology of $\mathrm{GABA}_{\mathrm{A}}$ and $\mathrm{GABA}_{\mathrm{B}}$ receptor subtypes, Trends Neurosci., 11 (1988) 112-116.

4 Bradley, R.M., Mistretta, C.M., Bates, C.A. and Killackey, H.P., Transganglionic transport of HRP from the circumvallate papilla of the rat, Brain Res., 361 (1985) 154-161.

5 Bradley, R.M. and Sweazey, R.D., Separation of neuron types in the gustatory zone of the nucleus tractus solitarius based on intrinsic firing properties, J. Neurophysiol., 67 (1992) 1659-1668.

6 Brand, J.G., Teeter, J.H. and Silver, W.L., Inhibition by amiloride of chorda tympani responses evoked by monovalent salts, Brain Res., 334 (1985) 207-214.

7 Brown, D.A., Collins, G.G.S. and Galvan, M., Influence of cellular transport on the interaction of amino acids with $\gamma$-aminobutyric acid (GABA)-receptors in isolated olfactory cortex of the guinea-pig, Br. J. Pharmacol., 68 (1980) 251-262.

8 Burt, D.R. and Kamatchi, G.L., GABA A $_{\text {receptor subtypes: from }}$ pharmacology to molecular biology, FASEB J., 5 (1991) 29162923.

9 Catelli Sved, J. and Sved, A.F., Cardiovascular responses elicited by gamma-aminobutyric acid in the nucleus tractus solitarius: evidence for action at the $\mathrm{GABA}_{\mathrm{B}}$ receptor, Neuropharmacology, 28 (1989) 515-520.

10 Catelli, J.M., Giakas, W.J. and Sved, A.F., GABAergic mechanisms in nucleus tractus solitarius alter blood pressure and vasopressin release, Brain Res., 403 (1987) 279-289.

11 Champagnat, J., Denavit-Saubié, M., Moyanova, S. and Rondouin, G., Involvement of amino acids in periodic inhibitions of bulbar respiratory neurones, Brain Res., 237 (1982) 351-365.

12 Crunelli, V., Haby, M., Jassik-Gerschenfeld, D., Leresche, N. and Pirchio, M., $\mathrm{Cl}^{-}$and $\mathrm{K}^{+}$-dependent inhibitory postsynaptic po- tentials evoked by interneurones of the rat lateral geniculate nucleus, J. Physiol., 399 (1988) 153-176.

13 Dekin, M.S., Getting, P.A. and Johnson, S.M., In vitro characterization of neurons in the ventral part of the nucleus tractus solitarius. I. Identification of neuronal types and repetitive firing properties, J. Neurophysiol., 58 (1987) 195-214.

14 DeSimone, J.A. and Ferrell, F., Analysis of amiloride inhibition of chorda tympani taste response of rat to NaCl, Am. J. Physiol., 249 (1985) R52-R61.

15 Dietrich, W.D., Lowry, O.H. and Loewy, A.D., The distribution of glutamate, GABA and aspartate in the nucleus tractus solitarius of the cat, Brain Res., 237 (1982) 254-260.

16 Doetsch, G.S. and Erickson, R.P., Synaptic processing of tastequality information in the nucleus tractus solitarius of the rat, $J$. Neurophysiol., 33 (1970) 490-507.

17 Dutar, P. and Nicoll, R.A., Pre- and postsynaptic GABA ${ }_{B}$ receptors in the hippocampus have different pharmacological properties, Neuron, 1 (1988) 585-591.

18 Florentino, A., Varga, K. and Kunos, G., Mechanism of the cardiovascular effects of $\mathrm{GABA}_{\mathrm{B}}$ receptor activation in the nucleus tractus solitarii of the rat, Brain Res., 535 (1990) 264-270.

19 Formaker, B.K. and Hill, D.L., An analysis of residual $\mathrm{NaCl}$ taste response after amiloride, Am. J. Physiol., 255 (1988) R1002R1007.

20 Giza, B.K. and Scott, T.R., The effect of amiloride on tasteevoked activity in the nucleus tractus solitarius of the rat, Brain Res., 550 (1991) 247-256.

21 Halpern, B.P. and Nelson, L.M., Bulbar gustatory responses to anterior and to posterior tongue stimulation in the rat, $\mathrm{Am}$.J. Physiol., 209 (1965) 105-110.

22 Hamilton, R.B. and Norgren, R., Central projections of gustatory nerves in the rat, J. Comp. Neurol., 222 (1984) 560-577.

23 Hayama, T., Ito, S. and Ogawa, H., Responses of solitary tract nucleus neurons to taste and mechanical stimulations of the oral cavity in decerebrate rats, Exp. Brain Res., 60 (1985) 235-242.

24 Hwang, B.H. and $\mathrm{Wu}, \mathrm{J} .-\mathrm{Y}$., Ultrastructural studies on catecholaminergic terminals and GABAergic neurons in nucleus tractus solitarius of the rat medulla oblongata, Brain Res, 302 (1984) $57-67$.

25 Kangrga, I., Jiang, M. and Randic, M., Actions of (-)-baclofen on rat dorsal horn neurons, Brain Res., 562 (1991) 265-275.

$26 \mathrm{Kubo}$, T. and Kihara, M., Evidence for $\gamma$-aminobutyric acid receptor-mediated modulation of the aortic baroreceptor reflex in the nucleus tractus solitarii of the rat, Neurosci. Lett., 89 (1988) 156-160.

27 Lasiter, P.S., Effects of early postnatal receptor damage on dendritic development in gustatory recipient zones of the rostral nucleus of the solitary tract, Dev. Brain Res., 61 (1991) 197-206.

28 Lasiter, P.S. and Kachele, D.L., Organization of GABA and GABA-transaminase containing neurons in the gustatory zone of the nucleus of the solitary tract, Brain Res. Bull, 21 (1988) 623-636.

29 Lasiter, P.S., Wong, D.M. and Kachele, D.L., Postnatal development of the rostral solitary nucleus in rat: Dendritic morphology and mitochondrial enzyme activity, Brain Res. Bull., 22 (1989) 313-321.

30 Maley, B. and Newton, B.W., Immunohistochemistry of $\gamma$ aminobutyric acid in the cat nucleus tractus solitarius, Brain Res., 330 (1985) 364-368.

31 McWilliam, P.N. and Shepheard, S.L., A GABA-mediated inhibition of neurones in the nucleus tractus solitarius of the cat that respond to electrical stimulation of the carotid sinus nerve, $\mathrm{Neu}$ rosci. Lett., 94 (1988) 321-326.

32 Meeley, M.P., Ruggiero, D.A., Ishitsuka, T. and Reis, D.J., Intrinsic gamma-aminobutyric acid neurons in the nucleus of the solitary tract and the rostal ventrolateral medulla of the rat: an immunocytochemical and biochemical study, Neurosci. Lett., 58 (1985) 83-89.

33 Miller Jr., I.J. and Bartoshuk, L.M., Taste perception, taste bud distribution, and spatial relationships. In T.V. Getchell, R.L. Doty, L.M. Bartoshuk and J.B.J. Snow Jr. (Eds.), Smell and Taste in Health and Disease, Raven, New York, 1991, pp. 205-233. 
34 Mittman, S., Flaming, D.G., Copenhagen, D.R. and Belgum, J.H., Bubble pressure measurement of micropipet tip outer diameter, J. Neurosci. Methods, 22 (1987) 161-166.

35 Nakagawa, T., Wakamori, M., Shirasaki, T., Nakaye, T. and Akaike, N., Gamma-aminobutyric acid-induced response in acutely isolated nucleus solitarii neurons of the rat, Am. J. Physiol. Cell Physiol., 260 (1991) C745-C749.

36 Newberry, N.R. and Nicoll, R.A., Comparison of the action of baclofen with $\gamma$-aminobutyric acid on rat hippocampal pyramidal cells in vitro, J. Physiol, 360 (1985) 161-185.

37 Nicoll, R.A., Malenka, R.C. and Kauer, J.A., Functional comparison of neurotransmitter receptor subtypes in mammalian central nervous system, Physiol. Rev., 70 (1990) 513-565.

38 Nuding, S.C. and Frank, M.E., Differential effects of amiloride on taste neurons in the hamster solitary nucleus, Chem. Senses, 17 (1992) 678

39 Ogawa, H., Imoto, T. and Hayama, T., Responsiveness of solitario-parabrachial relay neurons to taste and mechanical stimulation applied to the oral cavity in rats, Exp. Brain Res., 54 (1984) 349-358.

40 Richards, C.D. and Sercombe, R., Calcium, magnesium and the electrical activity of guinea-pig olfactory cortex in vitro, $J$. Physiol., 211 (1970) 571-584.

41 Scholfield, C.N., Intracellular and extracellular recordings in the isolated olfactory cortex slice and some problems associated with assessing drug action. In G.A. Kerkut and H.V. Wheal (Eds.), Electrophysiology of Isolated Mammalian CNS Preparations, Academic Press, London, 1981, pp. 133-152.

42 Shapovalov, A.I., Shiriaev, B.I. and Velumian, A.A., Mechanisms of post-synaptic excitation in amphibian motoneurones, $J$. Physiol., 279 (1978) 437-455.

43 Siggins, G.R. and Gruol, D.L., Mechanisms of transmitter action in the vertebrate central nervous system. In F.E. Bloom (Ed.), Handbook of Physiology, Section 1, The Nervous System, Vol IV, Intrinsic Regulatory Systems of the Brain, American Physiological Soc., Bethesda, 1986, pp. 1-114.

44 Smith, J.C. and Feldman, J.L., Central respiratory pattern gener- ation studied in an in vitro mammalian brainstem-spinal cord preparation. In G.C. Sieck, S.C. Gandevia and W.E. Cameron (Eds.), Respiratory muscles and their neuromotor control, Alan R. Liss, Inc., New York, 1987, pp. 27-36.

45 Staley, K.J., Otis, T.S. and Mody, I., Membrane properties of dentate gyrus granule cells: Comparison of sharp microelectrode and whole-cell recordings, J. Neurophysiol., 67 (1992) 1346-1358.

46 Sved, A.F. and Sved, J.C., Endogenous GABA acts on GABA receptors in nucleus tractus solitarius to increase blood pressure, Brain Res., 526 (1990) 235-240.

47 Sweazey, R.D. and Smith, D.V., Convergence onto hamster medullary taste neurons, Brain Res., 408 (1987) 173-184.

48 Takahashi, T., Membrane currents in visually identified motoneurones of neonatal rat spinal cord, $J$. Physiol., 423 (1990) 27-46.

49 Travers, J.B., Efferent projections from the anterior nucleus of the solitary tract of the hamster, Brain Res., 457 (1988) 1-11.

50 Travers, J.B. and Smith, D.V., Gustatory sensitivities in neurons of the hamster nucleus tractus solitarius, Sens. Process, 3 (1979) $1-26$.

51 Travers, J.B., Travers, S.P. and Norgren, R., Gustatory neural processing in the hindbrain, Annu. Rev. Neurosci., 10 (1987) $595-632$.

52 Vogt, M.B. and Mistretta, C.M., Convergence in mammalian nucleus of solitary tract during development and functional differentiation of salt taste circuits, J. Neurosci., 10 (1990) 3148-3157.

53 Wang, Y.T. and Bieger, D., Role of solitarial GABAergic mechanisms in control of swallowing, Am. J. Physiol. Regul. Integr. Comp. Physiol., 261 (1991) R639-R646.

54 Whitehead, M.C., Anatomy of the gustatory system in the hamster: synaptology of facial afferent terminals in the solitary nucleus, J. Comp. Neurol., 244 (1986) 72-85.

55 Whitehead, M.C., Subdivisions and neuron types of the nucleus of the solitary tract that project to the parabrachial nucleus in the hamster, J. Comp. Neurol., 301 (1990) 554-574.

56 Whitehead, M.C., Distribution of synapses on identified cell types in a gustatory subdidvision of the nucleus of the solitary tract, J. Comp. Neurol., in Press. 